\title{
Breeding of high lipid producing strain of Geotrichum robustum by ion beam implantation
}

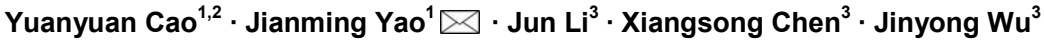 \\ 1 Laboratory of Ion Beam Bioengineering, Institute of Plasma Physics, Chinese Academy of Sciences, PR China \\ 2 College of Life Science, Anhui Agricultural University, PR China \\ 3 Anhui Academy of Recycling Economical and Technical Engineering, PR China
}

$\triangle$ Corresponding author: yy721@hotmail.com

Received May 18, 2010 / Accepted August 19, 2010

Published online: November 15, 2010

(c) 2010 by Pontificia Universidad Católica de Valparaíso, Chile

\begin{abstract}
To obtain an industrial strain with high lipid yield, the wild strain G0 of Geotrichum robustum was mutated by means of nitrogen ions implantation. Mutagenic effects of strain $\mathrm{G} 0$ by low energy $\mathrm{N}^{+}$ ion implantation were studied. The experimental results indicated that the survival rate curve took a "saddle" shape, and the positive mutation rate was increased to $22.00 \%$ at the dose of nitrogen ions $2.0 \times 10^{15}$ ions $/ \mathrm{cm}^{2}$ when the survival rate was $28.60 \%$. By repeated screening, a high lipid producing strain G9 was obtained. The biomass, lipid content and lipid yield of the mutant can reach $40.25 \mathrm{~g} / \mathrm{L}$, $71.14 \%$ and $28.63 \mathrm{~g} / \mathrm{L}$ after cultured in a $5 \mathrm{~L}$ fermenter for 8 days, increasing by $52.81 \%, 68.82 \%$ and $157.93 \%$ to those of wild strain, respectively. Analysis results on fatty acids composition and relative content by gas chromatography and mass spectrometry showed that the lipid in strain G9 was mainly composed of 16 -carbon and 18-carbon fatty acids, including $37.360 \%$ oleic acid, $23.631 \%$ palmitic acid, $4.458 \%$ linoleic acid and $26.465 \%$ stearic acid. Such compositional features were quite similar to plant oil. Geotrichum robustum strain G9 may be an ideal high lipid producing strain for biodiesel production.
\end{abstract}

Keywords: fatty acids, Geotrichum robustum, high lipid producing strain, ion beam implantation

\section{INTRODUCTION}

With the gradually exhaustion of fossil resources and increasingly environmental pollution, searching for alternative fuels, not only sustainable but also environment friendly (Barnwal and Sharma, 2005), has drawn more and more attention. Biodiesel as a kind of clean and renewable fuel (Canoira et al. 2006) has attracted increasing research interest. However, the high costs of biodiesel have become the bottleneck of its development. Currently, most raw materials of biodiesel come from higher plants, but the lower photosynthetic productivity of plants being chosen and competitive land demand lead to the result that the cost of raw materials accounts for $70 \%$ to $85 \%$ of the total cost of the biodiesel fuel (Gerpen, 2005), which limited the popularization of biodiesel. Studies indicated that some microorganisms including bacteria, yeasts, molds and algae can accumulate lipids over $20 \%$ of their dry biomass, which are defined as oleaginous species (Ratledge and Wynn, 2002). Because of their rapid reproduction and high lipid contents, microorganisms have greater potentials in biodiesel production in comparison to other oil crops. Now more and more studies are focused on oleaginous microorganisms (Papanikolaou et al. 2002; Ratledge, 2002; Papanikolaou et al. 2004), but problems of low biomass and lipid content are existed yet. So there is still a long distance from large-scale production. Breeding of high-productive lipid producing strain is the basis of the industrialization for microbial lipid. Mutagenesis is one of the effective means to obtain high-yield strains.

Ion implantation biology is a new interdiscipline originated from China in the mid-eighties of last century. Due to its high mutation rate and wide mutational spectrum with relatively low damage for the organisms being implanted (Feng et al. 2006; Yang et al. 2007; Yu, 2007), the low energy ion beam has been widely used for breeding of crops and microbes in agriculture and industry (Tanaka et al. 
2002; Pang et al. 2009; Yu et al. 2009; Zhang et al. 2010). In this work, a wild strain G0 of Geotrichum robustum was mutagenized by means of nitrogen ion implantation for breeding of high lipid producing strains. The parameters of $\mathrm{N}^{+}$implantation were studied, changes in biomass, liquid contents and liquid yields of wild type strain and mutant strain in the fermentation process were compared, and the fatty acids compositions as well as relative contents in the two strains were analyzed by gas chromatography and mass spectrometry (GC-MS). A high lipid producing strain for the production of biodiesel was expected to be obtained.

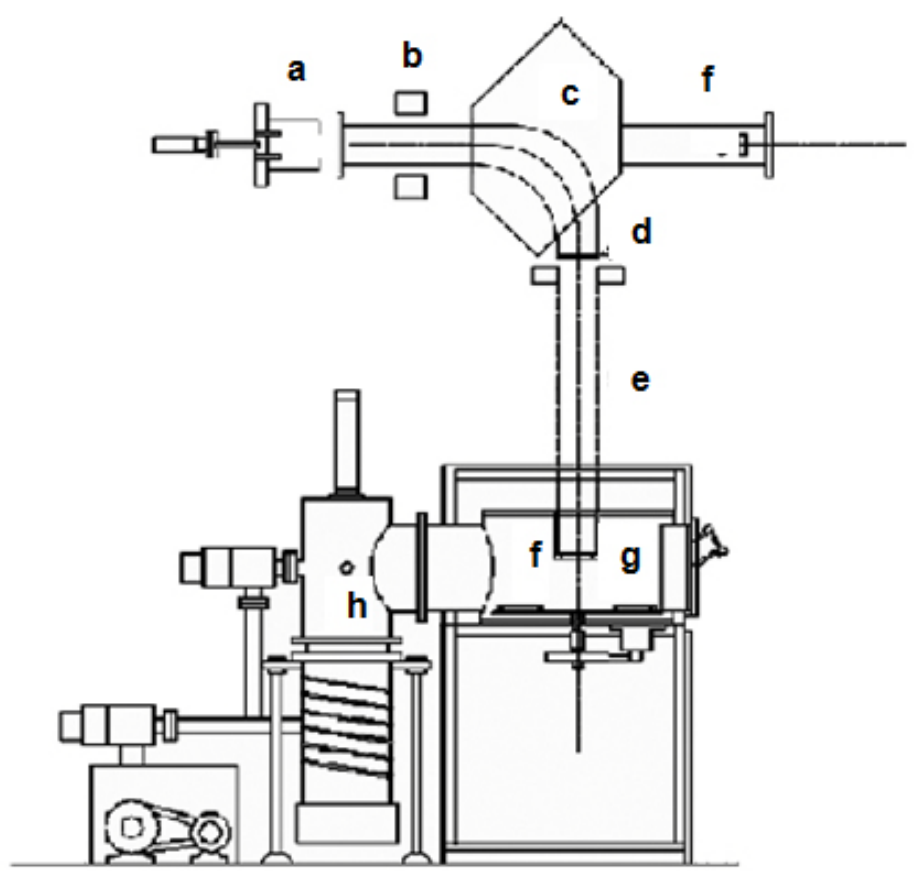

Fig. 1 Schematic diagram of an ion beam line. (a) lon source. (b) Focusing lens. (c) Mass analyzer. (d) Diaphragm. (e) Accelerating tube. (f) Measurement devices. (g) Target chamber. (h) Vacuum system.

\section{MATERIALS AND METHODS}

\section{Strain and media}

Geotrichum robustum G0 strain was obtained from Agricultural Culture Collection of China.

The YEPD medium contained the following constituents $(\mathrm{m} / \mathrm{v}): 2 \%$ glucose, $1 \%$ yeast power, $1 \%$ peptone, $\mathrm{pH}$ 5.8 6.0; the solid YEPD medium was the YEPD medium with $1.5 \%$ agar powder. The seed medium contained the following constituents $(\mathrm{m} / \mathrm{v}): 5 \%$ glucose, $2 \%$ yeast extract, $2 \%$ peptone, $0.5 \% \quad \mathrm{MgSO}_{4} \cdot 7 \mathrm{H}_{2} \mathrm{O}, \quad 0.3 \% \quad \mathrm{KNO}_{3}, 0.1 \% \quad \mathrm{NH}_{4} \mathrm{H}_{2} \mathrm{PO}_{4}, 0.2 \% \quad\left(\mathrm{NH}_{4}\right)_{2} \mathrm{SO}_{4}, \mathrm{pH}$ 5.8 6.0. The $\mathrm{N}$-limited fermentation medium contained $(\mathrm{m} / \mathrm{v})$ : $5 \%$ glucose, $0.05 \%$ yeast extract, $0.05 \%$ peptone, $1.5 \%$ $\mathrm{KH}_{2} \mathrm{PO}_{4}, 0.5 \% \mathrm{MgSO}_{4} \cdot 7 \mathrm{H}_{2} \mathrm{O}, 2 \%$ peanut meal, $\mathrm{pH}$ 5.8 6.0.

\section{Ion beam implantation equipment}

Implantation sources were produced by an ion beam bioengineering instrument (Patent No.ZL93103361.6, Zengliang Yu et al. 2009, Hefei, People's Republic of China) devised by CASIPP (Institute of Plasma Physics, Chinese Academy of Sciences). The implantation equipment is composed of 7 basic sections as shown in Figure 1. The operational principle of the instrument is as following: plasma is generated by ion source, and ions beam is led out by extraction system for acceptance selection by mass analyzer. Then the ions gain energy in accelerating device, and from then on the 
ions are ready for sample injection. A vacuum system provides the fundamental guarantee for obtaining the ion beam, and a focusing system is installed for the control of beam spreading.

\section{Ion beam implantation mutagenesis}

The culture of Geotrichum robustum strain G0 in log phase was broken to single spores by glass beads, and was filtered through four-layer sterile lens paper. Then the sample was diluted to an appropriate concentration, with $15 \%$ glycerin as protector. $0.1 \mathrm{~mL}$ of these samples were spread on sterile plates, which were dried with sterile air, and then implanted by nitrogen ion beam with energy of $10 \mathrm{keV}$ (kilo electron volts) in a dry, vacuum state. The fluence of ion beam was designed at $0 \mathrm{~N}^{+} / \mathrm{cm}^{2}$, $5 \times 10^{14} \mathrm{~N}^{+} / \mathrm{cm}^{2}, 1.0 \times 10^{15} \mathrm{~N}^{+} / \mathrm{cm}^{2}, 1.5 \times 10^{15} \mathrm{~N}^{+} / \mathrm{cm}^{2}, 2.0 \times 10^{15} \mathrm{~N}^{+} / \mathrm{cm}^{2}, 2.5 \times 10^{15} \mathrm{~N}^{+} / \mathrm{cm}^{2}, 3.0 \times$ $10^{15} \mathrm{~N}^{+} / \mathrm{cm}^{2}$, respectively. Meanwhile the control samples were in vacuum without irradiation.

After implantation, the samples were washed with $1 \mathrm{~mL}$ of sterile physiological saline respectively, 0.1 $\mathrm{mL}$ of each were spread on plates of YEPD medium, and the number of colonies and the survival rates of the strain were calculated after cultured for 3 days at $28^{\circ} \mathrm{C}$.

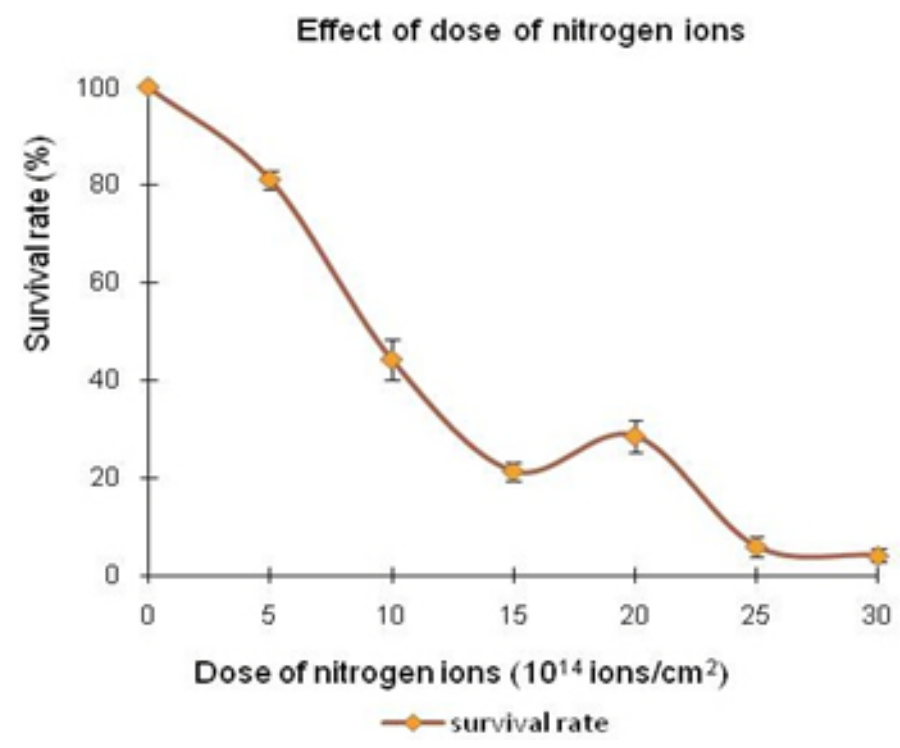

Fig. 2 Effect of dose of nitrogen ions on the survival rate of strain G0. Data were average values of three independent experiments. Error bars indicate SEs of mean values.

\section{Determination of mutation rate}

The criterion for mutants was defined as that the strains whose oil production was $10 \%$ higher/lower than that of the control strains were considered as positive/negative mutants. The calculation formula of the mutation rate was as $\left(M_{1}-M_{0}\right) / N$, where $M_{1}$ represents the number of mutation colonies in ion beam treated plates, $\mathrm{M}_{0}$ the number of mutation colonies in vacuum control plates and $\mathrm{N}$ the number of the total colonies screened. The final data of the mutation rate was the average value of three independent experiments.

\section{Mutant selection}

Colonies larger than unirradiated colonies were picked for re-screening. After cultured in seed medium under the condition of $28^{\circ} \mathrm{C}$ and $180 \mathrm{r} / \mathrm{min}$ for $24 \mathrm{hrs}$, the samples were inoculated into $20 \mathrm{~mL} \mathrm{~N}$-limited fermentation medium at $5 \%$, and cultured for 7 days under the same conditions. Vanillin phosphate reaction (Izard and Limberger, 2003) was employed to analyze the lipid content of these cultures, and the strains with higher lipid content were re-screened through Soxhlet extractor method (Yin, 2000) for obtaining high lipid strains. 


\section{Experiments in $5 \mathrm{~L}$ fermenter}

Seed cultures of $24 \mathrm{hrs}$ of both original and mutant strains were inoculated at $5 \%$ into $\mathrm{N}$-limited medium in $5 \mathrm{~L}$ fermenters with $1 \%$ antifoamer, and the fermenters were run at $28^{\circ} \mathrm{C}, 150 \mathrm{r} / \mathrm{min}$ and $1: 0.6 \mathrm{vvm}$ of ventilation. Glucose was added to the media at $2 \%$ per day, and the fermentation liquors were sampled each day to determine the dry weight and lipid yield of the two strains. The fermentation liquors were centrifuged at $3500 \mathrm{rpm}$, the sediments were washed 3 times and dried in $105^{\circ} \mathrm{C}$ to constant weight. Cell of the strains were broken by method of acid treatment (Yin, 2000), and then the lipid yield of the two strains could be measured by Soxhlet extractor method (Yin, 2000).

\section{Analysis on fatty acids compositions}

The fatty acid compositions were determined by gas chromatography-mass spectrometry (GC-MS). Before injection, fatty acids should first be treated by methyl esterification. The operating steps were as following: lipid was extracted by Soxhlet extractor from cells cultured in $5 \mathrm{~L}$ fermenter for 7 days, $0.1 \mathrm{~g}$ of which was diluted to $1 \sim 2 \mathrm{~mL}$ mixture of petroleum ether $\left(30 \sim 60^{\circ} \mathrm{C}\right)$ and benzene $(1: 1)$ with oscillation to help dissolution. 1 2 $\mathrm{mL}$ of $0.4 \mathrm{M} \mathrm{KOH}$-methanol solution was then added, and the mixture was shaken up before being stood at room for 5 10 min. $12 \mathrm{~mL}$ water was added to the mixture, and after agitated the supernatant could be injected into the GC-MS for analysis of fatty acids compositions.

GC (gas chromatography) analyses were performed on an Agilent 7890A gas chromatograph (Agilent Technologies Inc., Santa Clara, USA) employing a $30 \mathrm{~m} \times 0.25 \mathrm{~mm} \times 0.25 \mu \mathrm{m}$ HP - $5 \mathrm{~ms}$ fused-silica capillary column (J\&W Scientific from Agilent Technologies). The samples $(1 \mu \mathrm{L})$ were injected in the split mode (split ratio 20:1) using helium as carrier gas at a constant flow of $1 \mathrm{~mL} / \mathrm{min}$ and an inlet temperature of $250^{\circ} \mathrm{C}$. The column onset temperature was $80^{\circ} \mathrm{C}$, then the temperature programmed at $4^{\circ} \mathrm{C} / \mathrm{min}$ to $240^{\circ} \mathrm{C}$, which was held for $3 \mathrm{~min}$, and then programmed to $280^{\circ} \mathrm{C}$ at a rate of $10^{\circ} \mathrm{C} / \mathrm{min}$. MS analysis was performed using an Agilent MSD 5975C mass spectrometer (Agilent Technologies Inc., Santa Clara, USA) operated in electron-impact (EI) ionization mode. Electron energy was $70 \mathrm{eV}$. The ion source temperature was $230^{\circ} \mathrm{C}$ and the quadrupole temperature was $150^{\circ} \mathrm{C}$.

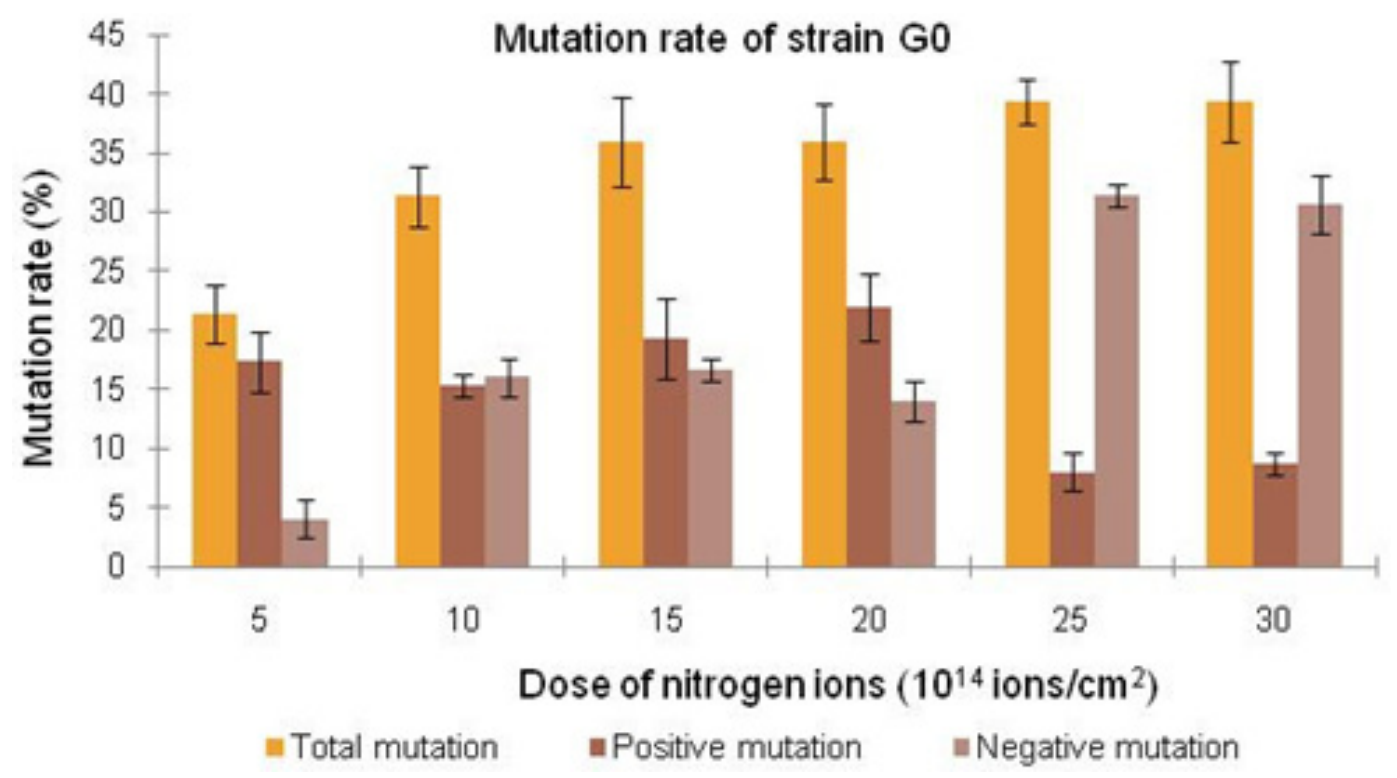

Fig. 3 Mutation rate of strain $\mathbf{G 0}$ exposed to $\mathbf{N}^{+}$at energy of $10 \mathrm{keV}$. Data were average values of three independent experiments. Error bars indicate SEs of mean values. 


\section{RESULTS}

\section{Effects of ion beam irradiation}

The effects of nitrogen ion radiation to strain $\mathrm{G} 0$ on survival rate are shown in Figure 2. The survival rate was related to the dose of $\mathrm{N}^{+}$implantation and showed a characteristic curve shaped like a saddle. Firstly, in the range of 0 ions $/ \mathrm{cm}^{2}$ to $1.5 \times 10^{15} \mathrm{ions} / \mathrm{cm}^{2}$, the survival rate decreased along with the increase of radiation dose, then increased temporarily within a short range of $1.5 \times 10^{15}$ ions $/ \mathrm{cm}^{2}$ to 2.0 $x 10^{15}$ ions $/ \mathrm{cm}^{2}$, and finally decreased as the dose continued to increase. The falling, rising, and then falling survival pattern was called "saddle curve" (Su et al. 2006; Xu et al. 2010) which was quite different from the "exponential shape" results of other traditional irradiation mutagens, such as UV and v-ray.

The mutation rates induced by nitrogen ion implantation are shown in Figure 3 . The mutation rate of strain $\mathrm{G0}$ was greatly increased by $\mathrm{N}^{+}$implantation, the survival rate of the strain increased from $21.40 \%$ to $28.60 \%$ when the dose of nitrogen ions increased from $1.5 \times 10^{15}$ ions $/ \mathrm{cm}^{2}$ to $2.0 \times 10^{15}$ ions $/ \mathrm{cm}^{2}$, and the highest positive mutation rates were achieved. This fact confirmed the theory that the highest positive mutation rate was obtained when the lethal rate of the microorganism ranges from $70 \%$ to $80 \%$ (Zhu and Wang, 1992). Dose of $2.0 \times 10^{15}$ ions $/ \mathrm{cm}^{2}$ was chosen for ion implantation in the following tests.

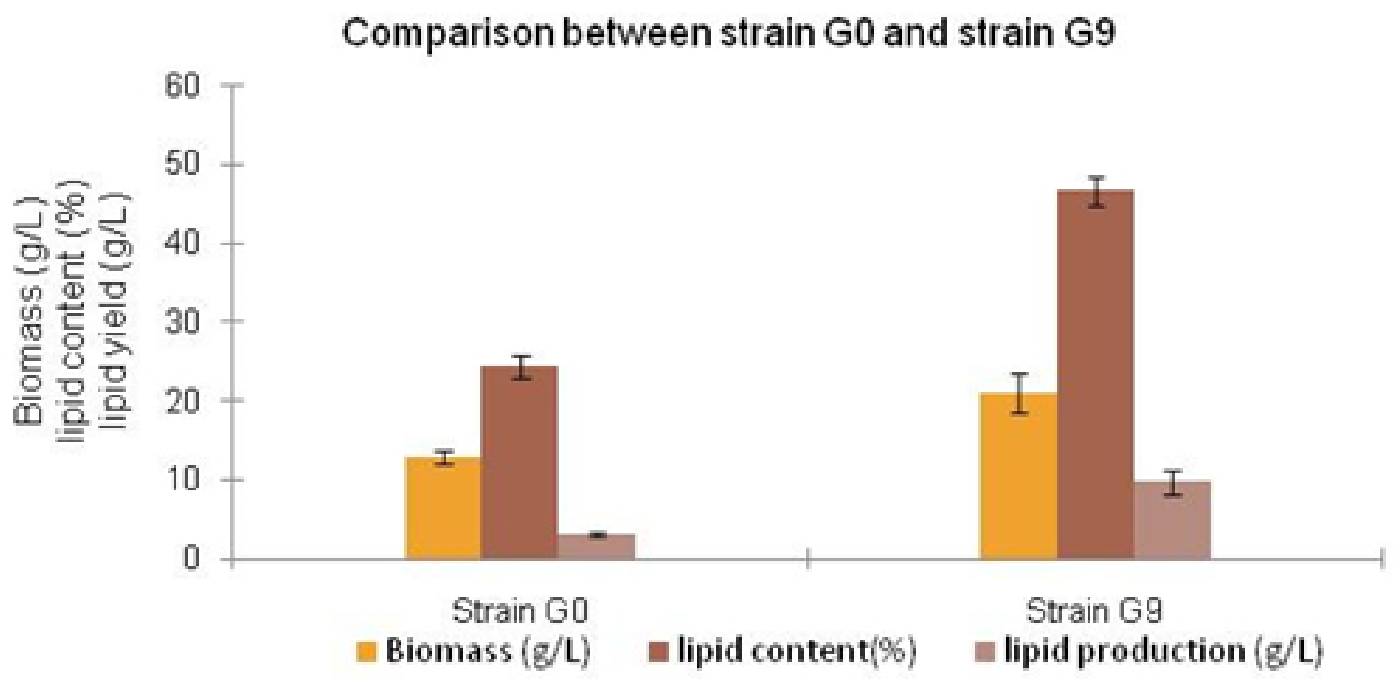

Fig. 4 Comparison between strain G0 and strain G9. Data were average values of three independent experiments. Error bars indicate SEs of mean values.

\section{Screening results of high lipid strain}

Nitrogen ions with $10 \mathrm{keV}$ and $2.0 \times 10^{15}$ ions $/ \mathrm{cm}^{2}$ were implanted to the original strain $\mathrm{G} 0$. By repeated screening, a high lipid producing strain G9 was obtained. After cultured for 7 days in $\mathrm{N}$-limited fermentation medium with the addition of $1 \%$ glucose per day under the condition of $28^{\circ} \mathrm{C}, 180 \mathrm{rpm}$ in $500 \mathrm{~mL}$ flasks, biomass (dry weight) and lipid content (percentage in dry weight) of strain G0 and G9 were determined, and lipid yield per liter fermentation liquor were calculated. The comparison between strain G0 and G9 was shown in Figure 4. The biomass and the lipid content of strain G9 reached 20.94 $\mathrm{g} \mathrm{L}^{-1}$ and $46.65 \%$, increasing by $62.83 \%$ and $91.90 \%$ compared with the original strain, respectively. The result that the lipid yield of strain $\mathrm{G} 9$ reached $9.81 \mathrm{~g} \mathrm{~L}^{-1}$, being 3.12 times to that of strain $\mathrm{G} 0$, demonstrated that strain G9 has much higher lipid than the original strain. 


\section{Results of experiments in 5L fermenter}

The fermentation characteristics of strain G0 and strain G9 are shown in Figure 5. The maximal biomass and lipid content of strain G9 reached $51.83 \mathrm{~g} / \mathrm{L}$ and $71.14 \%$, increasing by $71.96 \%$ and $37.26 \%$ compared with the original strain, respectively. Lipid yields of the two strains reached its highest at day 8 , and the yield of strain $G 9$ reached $28.63 \mathrm{~g} / \mathrm{L}$ being 2.58 times of that of the original strain. The results indicated that Geotrichum robustum G9 strain might be an excellent high lipid producing strain.

\section{Analysis on fatty acids compositions}

The chromatograms of methyl fatty acids in strain G0 and G9 are shown in Figure 6 and Figure 7. Through chromatographic peak analysis, based on mass spectrum information obtained from United States NIST 05 Standard Spectral Library, combined with manual parsing, the fatty acids compositions were determined, and by peak area normalization method the relative contents of these fatty acids were calculated. The results were listed in Table 1. From the table we can find that types of fatty acids in strain G9 are more than those in strain G0. Fatty acids such as pentadecanoic acid, 2-hexyl cyclopropaneoctanoic acid, 8-eicosenoic acid, behenic acid, tricosanoic acid, pentacosanoic acid and hexacosanoic acid are present in strain G9, but absent in strain G0. The lipid in strain G9 is mainly composed of 16 -carbon and 18 -carbon fatty acids, including $37.360 \%$ oleic acid, $23.631 \%$ palmitic acid, $4.458 \%$ linoleic acid and $26.465 \%$ stearic acid. Such compositional features are quite similar to plant oil, the widely used feedstock for biodiesel at present. Therefore, the Geotrichum robustum G9 strain could be considered as ideal high lipid producing strain for biodiesel production.

Table 1. The fatty acids composition and relative content of strain G0 and strain G9.

\begin{tabular}{|c|c|c|c|c|c|}
\hline & & & Strain G0 & & Strain G9 \\
\hline Formula & Fatty acid & $t_{R}(\min )$ & $\begin{array}{c}\text { Relative content } \\
(\%)\end{array}$ & $t_{R}(\min )$ & $\begin{array}{c}\text { Relative content } \\
(\%)\end{array}$ \\
\hline $\mathrm{C}_{14} \mathrm{H}_{28} \mathrm{O}_{2}$ & Myristic acid & 24.326 & 1.372 & 24.329 & 0.664 \\
\hline $\mathrm{C}_{15} \mathrm{H}_{30} \mathrm{O}_{2}$ & Pentadecanoic acid & - & - & 26.973 & 0.266 \\
\hline $\mathrm{C}_{16} \mathrm{H}_{30} \mathrm{O}_{2}$ & Palmitoleic acid & 28.975 & 3.878 & 28.961 & 0.566 \\
\hline $\mathrm{C}_{16} \mathrm{H}_{32} \mathrm{O}_{2}$ & Palmitic acid & 29.646 & 30.728 & 29.727 & 23.631 \\
\hline $\mathrm{C}_{17} \mathrm{H}_{32} \mathrm{O}_{2}$ & $\begin{array}{l}\text { 2-hexyl cyclopropaneoctanoic } \\
\text { acid }\end{array}$ & - & - & 31.347 & 0.240 \\
\hline $\mathrm{C}_{17} \mathrm{H}_{34} \mathrm{O}_{2}$ & Heptadecanoic acid & 31.931 & 0.327 & 31.952 & 0.464 \\
\hline $\mathrm{C}_{18} \mathrm{H}_{32} \mathrm{O}_{2}$ & Linoleic acid & 33.494 & 6.224 & 33.521 & 4.458 \\
\hline $\mathrm{C}_{18} \mathrm{H}_{34} \mathrm{O}_{2}$ & Oleic acid & 33.779 & 36.485 & 33.932 & 37.360 \\
\hline $\mathrm{C}_{18} \mathrm{H}_{36} \mathrm{O}_{2}$ & Stearic acid & 34.351 & 17.996 & 34.525 & 26.465 \\
\hline $\mathrm{C}_{18} \mathrm{H}_{34} \mathrm{O}_{3}$ & $\begin{array}{l}\text { Cis-9,10-Epoxyoctadecanoic } \\
\text { acid }\end{array}$ & 37.554 & 0.976 & - & - \\
\hline $\mathrm{C}_{18} \mathrm{H}_{34} \mathrm{O}_{3}$ & 10-Oxooctadecanoic acid & 38.041 & 0.567 & - & - \\
\hline $\mathrm{C}_{20} \mathrm{H}_{38} \mathrm{O}_{2}$ & 8-Eicosenoic acid & - & - & 38.039 & 0.154 \\
\hline $\mathrm{C}_{20} \mathrm{H}_{40} \mathrm{O}_{2}$ & Arachidic acid & 38.604 & 0.430 & 38.621 & 0.974 \\
\hline $\mathrm{C}_{22} \mathrm{H}_{44} \mathrm{O}_{2}$ & Behenic acid & - & - & 43.120 & 0.753 \\
\hline $\mathrm{C}_{23} \mathrm{H}_{46} \mathrm{O}_{2}$ & Tricosanoic acid & - & - & 46.000 & 0.331 \\
\hline $\mathrm{C}_{24} \mathrm{H}_{48} \mathrm{O}_{2}$ & Lignoceric acid & 47.997 & 1.017 & 48.031 & 2.857 \\
\hline $\mathrm{C}_{25} \mathrm{H}_{50} \mathrm{O}_{2}$ & Pentacosanoic acid & - & - & 49.470 & 0.598 \\
\hline $\mathrm{C}_{26} \mathrm{H}_{52} \mathrm{O}_{2}$ & Hexacosanoic acid & - & - & 50.992 & 0.219 \\
\hline
\end{tabular}




\section{DISCUSSION}

Ion beams, as a new source of mutation, have been characterized by a high mutation rate and wide mutational spectrum with relatively low damage to the organisms implanted $(\mathrm{Yu}, 2007)$. It is a mutagenesis method combining physical effect and chemical effect. Ion beams can cause chromosomal aberration and lead to damage and fracture in DNA strand, so that genetic material can be changed in molecular level, and then lead to large increase in mutation frequency.

In this experiment, low-energy ion beams were used as a mutagen in the breeding of high lipid producing strains. Mutagenic effect of ion beam implantation on Geotrichum robustum G0 strain was studied. The dose-survival curve did not appear as "exponential shape" like those of other traditional mutagens such as UV and y-ray, but exhibited "down-up-down" saddle pattern. The mechanisms of low-energy ion irradiation are not totally understood yet. Lower dosage ions might only incur damage and etching of the cell surface, so the survival rate is higher, with dosage increasing the superficial injury to the cell becomes more serious, and massive free $\mathrm{OH}$ radicals cause the survival rate to drop, and with the continuative increase in dosage, some implanted ions might be deposited in the organism to form new compounds which may compete with free $\mathrm{OH}$ radicals reacting with DNA and thereby decreasing the degree of DNA damage (Shao and Yu, 1997). On the other hand, the nuclear collision process between a low-energy ion and a target molecule creates many types of active species and products which have been hypothesized and identified theoretically and experimentally. These may cause a new reconstituting process to increase the survival rate in high dose range in low-energy ion beam exposure (Su et al. 2006). However, when the dose further increases, the cell damage becomes irreparable, leading to a reduced survival rate again. This may explain the "saddle curve" in the doseeffect curve.

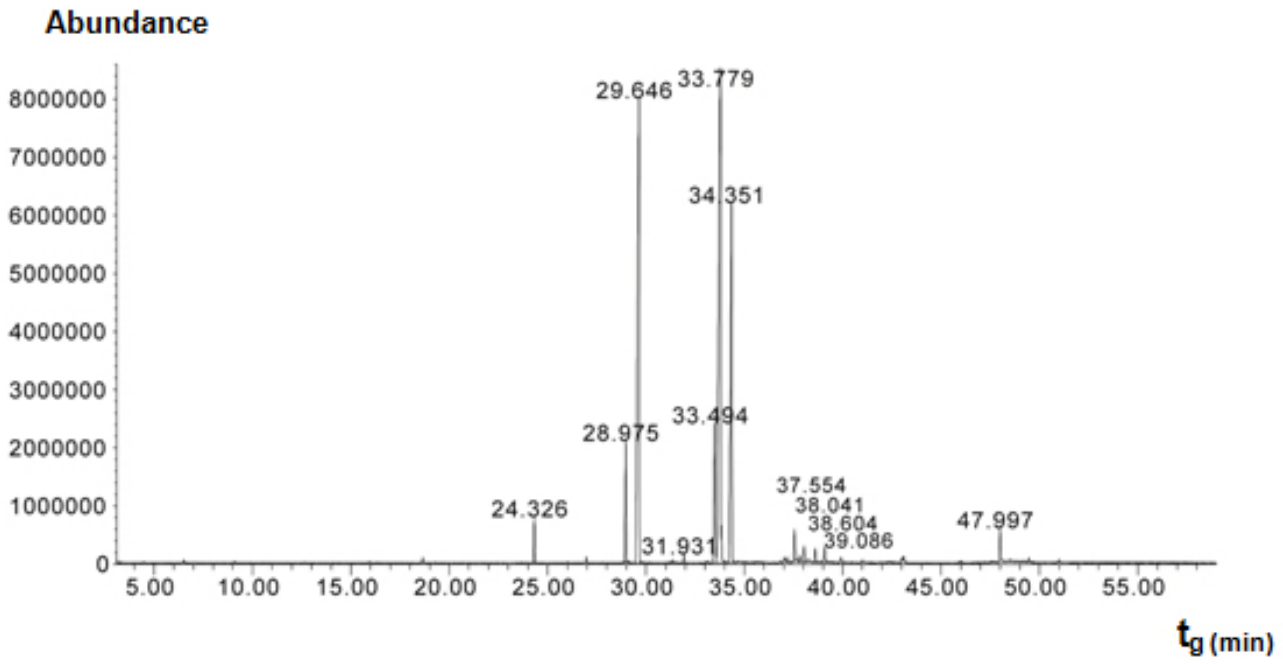

Fig. 6 The total ion current chromatogram of methyl fatty acids in strain G0.

The total mutation rate of strain G0 induce by nitrogen ion implantation was as high as $39.34 \%$ and the highest positive mutation rate reached to $22.00 \%$ when implantation dosage was at $2.0 \times 10^{15} \mathrm{~N}^{+} / \mathrm{cm}^{2}$, which showed a strong mutagenic effect of nitrogen ion implantation. The reason for this fact may probably exist the interactions between low-energy ions and the organisms, including energy deposition, momentum transferring, mass deposition and charge neutralization and/or exchange (Li et al. 2005), whereas UV and other ionizing radiations only produce the effect of energy deposition to organisms (Song et al. 2001).

Currently, study of biodiesel is one of the worldwide research focuses, and the source of economical raw materials of biodiesel is the principal problem to be solved urgently. Oleaginous microorganisms have advantages in biodiesel production compared to other oil crops. First, the cultivation of 
microorganisms does not need much land required by plants. It was reported that the transport fuel consumption in the United States with biodiesel will require 0.53 billion $\mathrm{m}^{3}$ of biodiesel annually at the current rate consumption which means $24 \%$ of total cropland would be needed to devote to $50 \%$ of transport fuel needs (Chisti, 2007), so it is not feasible to produce biodiesel from oil crops particularly in developing countries with limited arable land per capita. Second, oleaginous microorganisms grow extremely rapidly and are rich in oil. Li et al. (2006) reported that strain AS 2. 1389 of Rhodosporidium toruloides can accumulate high content of lipid (73.8\%) cultured in $7 \mathrm{~L}$ fermenter under the optimized experimental conditions with $19.2 \mathrm{~g} / \mathrm{L}$ strain biomass, and $14.2 \mathrm{~g} / \mathrm{L}$ lipid yield. Papanikolaou et al. (2004) reported that the strain Mortierella isabelina cultured in high-sugar content media got $35.9 \mathrm{~g} / \mathrm{L}$ strain biomass and 50 55\% of lipid content, the lipid yield of the strain reached $18.1 \mathrm{~g} / \mathrm{L}$. In this work, the strain Geotrichum robustum G0 was mutagenized by means of nitrogen ion implantation, a high lipid strain G9 was obtained. The biomass, lipid content and lipid yield of the mutant can reach 40.25 $\mathrm{g} / \mathrm{L}, 71.14 \%$ and $28.63 \mathrm{~g} / \mathrm{L}$, respectively, after cultured in $5 \mathrm{~L}$ fermenter for 8 days. Analysis results on fatty acids composition and relative content by GC-MS showed that strain G9 may be suitable as production strain for microbial oil and an ideal high lipid producing strain for biodiesel production.

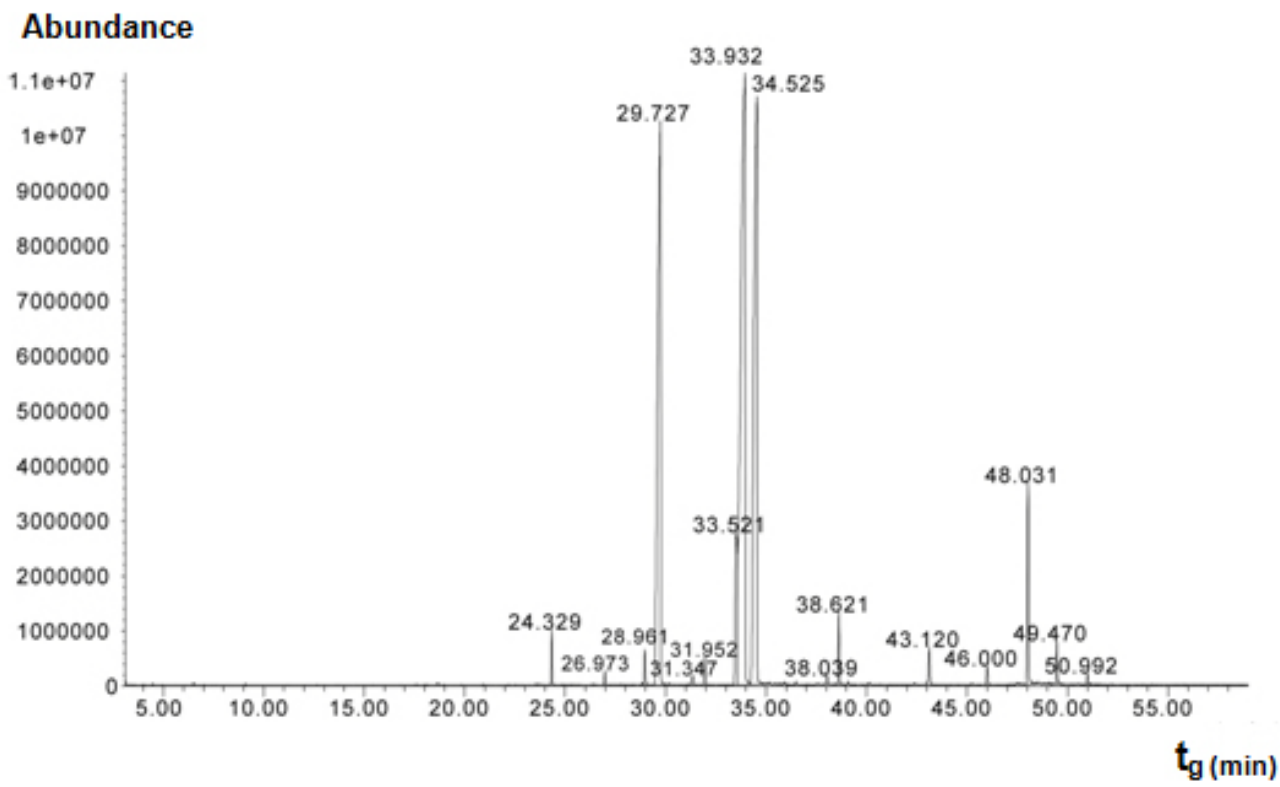

Fig. 7 The total ion current chromatogram of methyl fatty acids in strain G9.

Nevertheless, there is still a long way to large scale biodiesel production. To make the process of biodiesel production economically viable, further work should focus on searching for biomass wastes as substrates in place of the common $\mathrm{N}$-limited fermentation medium for culture of strain G9 of Geotrichum robustum, which has double advantages of resource reuse and lower cost. Furthermore, an economical, energy saving, environment-friendly industrial technology of fermentation should be established to reduce production costs effectively.

Financial support: Director Foundation of Institute of Plasma, Chinese Academy of Sciences (No. 095GZ1156X).

\section{REFERENCES}

BARNWAL, B.K. and SHARMA, M.P. (2005). Prospects of biodiesel production from vegetable oils in India. Renewable and Sustainable Energy Reviews, vol. 9, no. 4, p. 363-378. [CrossRef]

CANOIRA, L.; ALCANTARA, R.; GARCIA-MARTINEZ, M.J. and CARRASCO, J. (2006). Biodiesel from jojoba oilwax: Transesterification with methanol and properties as a fuel. Biomass and Bioenergy, vol. 30, no. 1, p. 7681. [CrossRef] 
CHISTI, Y. (2007). Biodiesel from microalgae. Biotechnology Advances, vol. 25, no. 3, p. 294-306. [CrossRef]

FENG, H.; YU, Z. and CHU, P.K. (2006). Ion implantation of organisms. Materials Science and Engineering: R: Reports, vol. 54, no. 3-4, p. 49-120. [CrossRef]

GERPEN, J. (2005). Biodiesel processing and production. Fuel Processing Technology, vol. 86, no. 10, p. 10971107. [CrossRef]

IZARD, J. and LIMBERGER, R.J. (2003). Rapid screening method for quantitation of bacterial cell lipids from whole cell. Journal of Microbiological Methods, vol. 55, no. 2, p. 411-418. [CrossRef]

LI, G.; HUANG, Q.; QIN, G. and HUO, Y. (2005). The effects of low-energy nitrogen ion implantation on pollen exine substructure and pollen germination of Cedrus deodara. Plasma Science and Technology, vol. 7, no. 6, p. 3176-3180. [CrossRef]

LI, Y.-H.; LIU, B.; ZHAO, Z.-B. and BAI, F.-W. (2006). Optimization of culture conditions for lipid production by Rhodosporidium toruloides. Chinese Journal of Biotechnology, vol. 22, no. 4, p. 650-656. [CrossRef]

PANG, M.; YAO, J. and WANG, D. (2009). A study of mutation breeding of high-yielding tryptophanase Escherichia coli by low-energy $\mathrm{N}^{+}$ion beam implantation. Plasma Science and Technology, vol. 11, no. 6, p. 744-749. [CrossRef]

PAPANIKOLAOU, S.; CHEVALOT, I.; KOMAITIS, M.; MARC, I. and AGGELIS, G. (2002). Single cell oil production by Yarrowia lipolytica growing on an industrial derivative of animal fat in batch cultures. Applied Microbiology and Biotechnology, vol. 58, no. 3, p. 308-312. [CrossRef]

PAPANIKOLAOU, S.; KOMAITIS, M. and AGGELIS, G. (2004). Single cell oil (SCO) production by Mortierella isabellina grown on high-sugar content media. Bioresource Technology, vol. 95, no. 3, p. 287-291. [CrossRef]

RATLEDGE, C. (2002). Regulation of lipid accumulation in oleaginous micro-organisms. Biochemical Society Transactions, vol. 30, no. 6, p. 1047-1050. [CrossRef]

RATLEDGE, C. and WYNN, J.P. (2002). The biochemistry and molecular biology of lipid accumulation in oleaginous microorganisms. Advances in Applied Microbiology, vol. 51, p. 1-44. [CrossRef]

$\mathrm{SHAO}, \mathrm{C}$. and $\mathrm{YU}, \mathrm{Z}$. (1997). Mass deposition in tyrosine irradiated by a $\mathrm{N}^{+}$ion. Radiation Physics and Chemistry, vol. 50, no. 6, p. 595-599. [CrossRef]

SONG, D.-J.; WU, L.-F.; WU, L.-J. and YU, Z.-L. (2001). Dose effects of ion beam exposure on Deinococcus radiodurans: Survival and dose response. Plasma Science and Technology, vol. 3, no. 1, p. 665-672. [CrossRef]

SU, C.; ZHOU, W.; FAN, Y.; WANG, L; ZHAO, S. and YU, Z. (2006). Mutation breeding of chitosanase-producing strain Bacillus sp. S65 by low-energy ion implantation. Journal of Industrial Microbiology and Biotechnology, vol. 33, no. 12, p. 1037-1042. [CrossRef]

TANAKA, A.; SAKAMOTO, A.; ISHIGAKI, Y.; NIKAIDO, O.; SUN, G.; HASE, Y.; SHIKAZONO, N.; TANO, S. and WATANABE, H. (2002). An ultraviolet-B-resistant mutant with enhanced DNA repair in arabidopsis. Plant Physiology, vol. 129, no. 1, p. 64-71. [CrossRef]

XU, T.T.; BAI, Z.-Z.; WANG, L.-J. and He, B.-F. (2010). Breeding of D(-)-lactic acid high producing strain by lowenergy ion implantation and preliminary analysis of related metabolism. Applied Biochemistry and Biotechnology, vol. 160, no. 2, p. 314-321. [CrossRef]

YANG, Y.; FAN, Y.; LI, W.; WANG, D.; WU, Y.; ZHENG, Z. and YU, Z. (2007). Optimization of L(+)-lactic acid production from xylose with Rhizopus oryzae mutant RLC41-6 breeding by low-energy ion implantation. Plasma Science and Technology, vol. 9, no. 5, p. 638-642. [CrossRef]

YIN, J. (2000). The selection of lipid-producing yeast. Journal of Shaoxing College of Arts and Sciences, vol. 20, no. 5 , p. 60-61.

YU, Z. (2007). Study on the interaction of low-energy ions with organisms. Surface and Coatings Technology, vol. 201, no. 19-20, p. 8006-8013. [CrossRef]

YU, L.D.; KAMWANNA, T. and BROWN, I.G. (2009). The low-energy ion range in DNA. Physics in Medicine and Biology, vol. 54, no. 16, p. 5009-5022. [CrossRef]

ZHANG, X.; LIN, B.; GAO, X. and SHEN, H. (2010). Enhancement of wanlongmycin production by nitrogen ion beam implantation. Electronic Journal of Biotechnology, vol. 13, no. 1. [CrossRef]

ZHU, G. and WANG, Z. (1992). Laboratory technical handbook of industry microorganisms. Jiangsu, China Light Industry Press, 710 p. ISBN 7-5019-1584-9.

\section{How to cite this article:}

CAO, Y.; YAO, J.; LI, J.; CHEN, X. and WU, J. (2010). Breeding of high lipid producing strain of Geotrichum robustum by ion beam implantation. Electronic Journal of Biotechnology, vol. 13, no. 6. http://dx.doi.org/10.2225/vol13-issue6-fulltext-4 